\title{
Large volume sample introduction using temperature programmable injectors: Implications of liner diameter
}

Citation for published version (APA):

Mol, J. G. J., Janssen, J. G. M., Cramers, C. A. M. G., \& Brinkman, U. A. T. (1995). Large volume sample introduction using temperature programmable injectors: Implications of liner diameter. Journal of High Resolution Chromatography, 18(1), 19-27. https://doi.org/10.1002/jhrc.1240180106

DOI:

10.1002/jhrc.1240180106

Document status and date:

Published: 01/01/1995

\section{Document Version:}

Publisher's PDF, also known as Version of Record (includes final page, issue and volume numbers)

\section{Please check the document version of this publication:}

- A submitted manuscript is the version of the article upon submission and before peer-review. There can be important differences between the submitted version and the official published version of record. People interested in the research are advised to contact the author for the final version of the publication, or visit the $\mathrm{DOI}$ to the publisher's website.

- The final author version and the galley proof are versions of the publication after peer review.

- The final published version features the final layout of the paper including the volume, issue and page numbers.

Link to publication

\section{General rights}

Copyright and moral rights for the publications made accessible in the public portal are retained by the authors and/or other copyright owners and it is a condition of accessing publications that users recognise and abide by the legal requirements associated with these rights.

- Users may download and print one copy of any publication from the public portal for the purpose of private study or research.

- You may not further distribute the material or use it for any profit-making activity or commercial gain

- You may freely distribute the URL identifying the publication in the public portal.

If the publication is distributed under the terms of Article 25fa of the Dutch Copyright Act, indicated by the "Taverne" license above, please follow below link for the End User Agreement:

www.tue.nl/taverne

Take down policy

If you believe that this document breaches copyright please contact us at:

openaccess@tue.nl

providing details and we will investigate your claim. 


\title{
Large Volume Sample Introduction Using Temperature Programmable Injectors: Implications of Liner Diameter
}

\author{
Hans G.J. Mol*, Hans-Gerd Janssen, and Carel A. Cramers \\ Eindhoven University of Technology, Laboratory of Instrumental Analysis, P.O. Box 513, 5600 MB Eindhoven, The Netherlands
}

Udo A.Th. Brinkman

Free University, Department of Analytical Chemistry, De Boelelaan 1083, $1081 \mathrm{HV}$ Amsterdam, The Netherlands

\author{
Key Words: \\ Gas chromatography \\ Large volume injection \\ PTV injectors \\ PTV splitless injection \\ PTV solvent split injection
}

\section{Summary}

Temperature programmable injectors with liner diameters ranging from 1 to $3.5 \mathrm{~mm}$ are evaluated and compared for solvent split injection of large volumes in capillary gas chromatography. The liner dimensions determine whether a large sample volume can be introduced rapidly or has to be introduced in a speed controlled manner. The effect of the injection technique used on the recovery of $n$-alkanes is evaluated. Furthermore the influence of the liner diameter on the occurrence of thermal degradation during splitless transfer to the analytical column is studied. Guidelines are given for the selection of the PTV liner internal diameter best suited for specific applications.

\section{Introduction}

In trace analysis the introduction of large sample volumes is a simple and efficient way to increase analyte detectability. In capillary gas chromatography large volume injections can be carried out either by applying on-column injection using retention gaps [1] or by using temperature programmable (PTV) injectors. On-column injection is relatively simple and accurate but less suited for dirty samples as involatile sample constituents easily contaminate the column inlet which results in a poor long-term stability of the system [2,3]. This becomes even more true when dealing with large sample volumes. In this respect PTV based large volume injection techniques are clearly advantageous because here involatile matrix compounds remain deposited in the liner and generally cause less problems.

Already 15 years ago Vogt and co-workers $[4,5]$ constructed a temperature programmable injector and applied it for the introduction of large sample volumes (up to $250 \mu \mathrm{l}$ ) in biomedical and environmental applications. Despite their good results there has hardly been any interest in the PTV injector for large volume sampling in the first ten years following the publication of Vogt. In this period the PTV injector did, however, receive considerable attention as an alternative injector to conventional hot split/splitless injectors. The groups of Schomburg [6] and Poy et al. [7] demonstrated that temperature-programmed sample introduction offers a number of advantages in comparison with hot injection techniques. The most important one is that discrimination of high boiling analytes is virtually absent when the sample is injected into a cold chamber. Furthermore, the quantitative performance of PTV injection is much better compared to the hot injection techniques. Following these early PTV developments, there has been a renewed interest in the use of the PTV injector for large volume sample introduction in the last five years.

At present four techniques for large volume injection using PTV injectors can be distinguished. The first technique is the solvent split injection which was presented when the PTV injector was introduced $[4,5]$. Here the sample is injected with the split exit open at an injector temperature below the solvent boiling point. After elimination of the solvent the analytes retained in the liner are transferred to the analytical column in the splitless mode. The liner has to be packed, e.g. with glass wool, to prevent the liquid sample from being pushed to the base of the injector which results in losses via the split exit or in flooding of the column inlet. The maximum volume of liquid that can be held within the injector depends mainly on the dimensions of the liner and the amount of packing material. Sample volumes exceeding the maximum volume have to be introduced in several steps or, more elegantly, in a speed controlled manner. The time between two injections and the introduction speed, respectively, have to be adjusted to the solvent evaporation rate. Variables affecting the sampling process have been extensively discussed [8-10]. In liners packed with glass wool quantitative recoveries are found for compounds with a boiling point above that of $\mathrm{C}_{13}$ [9]. For more volatile analytes liners packed with selective adsorption materials are required or multidimensional $\mathrm{GC}$ systems have to be used $[11,12]$.

The second method for introducing large sample volumes using PTV injection devices is the so-called large volume splitless injection [13]. The sample is introduced at a temperature below or close to the pressure corrected boiling point of the solvent. During sample introduction the split valve is closed and the solvent is vented via the analytical column. Volatile compounds co-evaporating with the solvent are not lost via the split exit as is the case for the solvent split method described above, but are trapped in the swollen stationary phase of the analytical column. The flow rate through the liner is equal to the column flow rate which makes the time needed for solvent elimination much longer than in solvent split injection.

A third alternative for PTV large volume sampling was initially described as PTV vapor overflow [14]. Later the technique was carried out in conventional hot split/splitless injectors and somewhat confusingly called large volume splitless injection $[15,16]$. 
In the vapor overflow technique the sample is rapidly injected into the lower part of a packed liner at a temperature far above the boiling point of the solvent. The split exit is closed but the septum purge outlet is wide open. A violent evaporation causes most of the expanding solvent vapor and volatile solutes to escape through the septum purge outlet. Solutes of low volatility are retained at the cold spot in the liner created by evaporation of the solvent. After solvent evaporation the temperature of the evaporation zone returns to the injector temperature and transfer of the analytes into the column is initiated. When the liner is packed with glass wool losses occur for $n$-alkanes up to $\mathrm{C}_{25}$ [16]. With a Tenax packed liner quantitative recoveries were obtained for $\mathrm{C}_{20}$ and higher boiling compounds. The technique was also applied for direct injection of aqueous samples [17]. Here the application of the method is again restricted to higher boiling sample constituents.

The fourth technique for large volume injection using PTV injectors is adsorption/thermal desorption (or solid-phase extraction/thermal desorption). In contrast to the other techniques this method can only be applied for aqueous samples. The liner is packed with an adsorption material and the sample is pushed through the liner, in the liquid state, by a high flow of carrier gas. The analytes are sorbed onto the adsorption material. After drying the liner the analytes are thermally desorbed and transferred to the analytical column. During injection the split valve is open and the injector temperature is ambient or slightly higher. To prevent water from entering the GC column a counter current flow from the column towards the injector is applied. The method was applied for analysis of chlorobenzenes and chlorophenols in $100 \mu \mathrm{l}$ water samples [18]. Another application described the determination of various organic compounds in water volumes up to $1 \mathrm{ml}[19]$.

For the introduction of large volumes of organic solvents the adsorption/thermal desorption technique is not suited. From the other three techniques large volume splitless injection is less suited because solvent elimination is time consuming and the vapor overflow technique is only applicable to a narrow range of relatively high boiling compounds. In other words, the solvent split technique offers the best possibilities for large volume sample introduction using PTV injectors.

The current PTV injectors are almost exclusively equipped with narrow inserts, with typically $1 \mathrm{~mm}$ internal diameter (i.d.), to allow rapid vaporization of the analytes. As these liners can only hold $20-30 \mu 1$ of liquid [13], one is often compelled to apply speed controlled sample introduction. Here the introduction speed is a critical parameter which is affected by many experimental variables and requires careful optimization. In this work the use of PTV injectors equipped with liners with larger internal diameters, allowing rapid introduction of larger sample volumes, is evaluated. The effect of liner i.d. on the amount of solvent that can be held within the injector, the splitless transfer of analytes to the analytical column and on the occurrence of thermal degradation were studied. In addition the effect of solvent properties and PTV temperature on the recoveries of $n$-alkanes in large volume sampling were evaluated.

\section{Experimental}

\subsection{Instrumentation}

Three gas chromatographic systems equipped with three different PTV injectors were used. The first system consisted of a gas chromatograph (model 5890, Hewlett Packard, Avondale, PA, USA) equipped with a flame ionization detector and PTV No. 1 (PTV-1) (Optic, Ai Cambridge, Cambridge, UK). The liner dimensions were $80 \mathrm{~mm} \times 3.4 \mathrm{~mm}$ i.d. and $5.1 \mathrm{~mm}$ o.d. Two liners with the same external dimensions but smaller internal diameters, 1.2 and $2.2 \mathrm{~mm}$, were made in house. On-column injection was possible by using a special on-column insert. The second GC system consisted of a gas chromatograph (Autosystem, Perkin Elmer, Norwalk, CT, USA) provided with a flame ionization detector, a mass spectrometric detector (Q-mass 910) and PTV No. 2 (PTV-2) (PSS = programmable split/splitless injector, Perkin Elmer). The liner dimensions were $88 \mathrm{~mm} \times 2.3 \mathrm{~mm}$ i.d. $\times 4.0 \mathrm{~mm}$ i.d. The third gas chromatograph (model 5890 , Hewlett Packard) was equipped with a flame ionization detector and PTV No. 3 (PTV-3) (KAS, Gerstel, Mülheim a/d Ruhr, Germany). The carrier gas inlet system was modified as described earlier [9]. The liner dimensions were $92 \mathrm{~mm} \times 1.2 \mathrm{~mm}$ i.d. $\times 2.0 \mathrm{~mm}$ o.d.

All liners were packed with silanized glass wool (Perkin Elmer). PTV-1 and PTV-3 could be cooled to subambient temperatures with liquid carbon dioxide. All solvents were freshly distilled before use. Fatty acids were silylated as follows: in a $2 \mathrm{ml}$ vial $400 \mu \mathrm{l}$ of BSTFA (bistrimethylsilyltrifluoracetamide) were added to a mixture of decanoic acid, tetradecanoic acid, octadecanoic acid and docosanoic acid (10 $\mathrm{mg}$ each). The vial was closed and maintained at $65{ }^{\circ} \mathrm{C}$ for $30 \mathrm{~min}$. Next, the contents were diluted with $10 \mathrm{ml}$ of hexane. Manual injections were carried out rapidly, i.e. within 1-2 s, (called 'at-once injection') using $10,50,100$ or $250 \mu 1$ syringes (Hamilton) with $50 \mathrm{~mm}$ needles. Speed controlled sample introduction was carried out with a $1 \mathrm{ml}$ speed programmable syringe (SPS, Gerstel). For GC separation a $20 \mathrm{~m} \times 0.32 \mathrm{~mm}$ i.d. column coated with $0.5 \mu \mathrm{m}$ Ultra-1 was used applying helium as carrier gas. Data collection was done with an Omega integration system (Perkin Elmer).

\subsection{Temperature Profiles}

Temperature profiles inside the liners were measured with a thermocouple consisting of two $0.2 \mathrm{~mm}$ o.d. $\mathrm{Ni}-\mathrm{Cr} / \mathrm{Ni}$ wires which were inserted into the liner from the base of the injector, i.e. in the same manner as the column. To prevent electrical contact between the wires, one of them was inserted into a piece of $0.32 \mathrm{~mm}$ i.d. fused silica capillary. All temperature measurements were carried out with a helium flow through the injector. PTV-1 could be equipped with the standard $3.4 \mathrm{~mm}$ i.d. liner and with smaller i.d. but identical o.d. liners. Because of the thicker glass wall of the latter liners the time required for reaching the final temperature (inside the liner) was slightly longer: heating from 50 to $300{ }^{\circ} \mathrm{C}$ at $8 \% \mathrm{~s}$ took 4 seconds longer for the $1.2 \mathrm{~mm}$ i.d. insert than for the standard $3.4 \mathrm{~mm}$ i.d. insert. For PTV-2 the heating rate is limited. In case of heating ballistically from 50 to $300{ }^{\circ} \mathrm{C}$ the temperature increase inside the liner was measured to be approximately $3 \%$. Hence, splitless times can be relatively long with this injector. PTV injectors typically show a temperature gradient along the length axis of the liner. The temperatures 
in the upper and bottom part of the liner are lower than in the middle section due to heat losses to the surrounding atmosphere and the oven, respectively. Needle tip, column entrance and packing material were all positioned in the properly heated zone inside the liner of each PTV injector.

\section{Results and Discussion}

One of the main differences in the design of classical split/splitless injectors and PTV injectors is the vaporization chamber. To allow rapid heating, liners of PTV injectors are designed to have a low thermal mass. For that reason the internal diameter of PTV liners is generally smaller than that of conventional split/splitless injectors. Very rapid heating, i.e. faster than $c a 10 \%$, can be useful in cold split injection. Further the use of low-volume inserts can be beneficial for the separation efficiency in isothermal analysis. In most other applications, however, broad input bands caused by slow transfer of compounds from the liner to the column will be refocused by either cold trapping or solvent trapping. A disadvantage of the low internal volume of liners in the current PTV injectors is that only $20-30 \mu \mathrm{l}$ of liquid can be injected at once. For larger volumes losses of liquid sample will occur and speed controlled sample introduction has to be applied. Although the optimization of speed controlled sample introduction has been thoroughly discussed [8-10], direct rapid injection of the sample would greatly simplify the use of PTV injectors in large volume sampling. For classical splitsplitless injectors, equipped with ca $4 \mathrm{~mm}$ i.d. inserts, rapid injection of large volumes is possible $[15,20]$. Recently two new PTV injectors equipped with liners with larger internal diameters became commercially available. In the present contribution the performance of these injectors for large volume sampling is evaluated and the results compared with those obtained using a PTV injector equipped with a narrow liner. The sampling procedure for large volume injection with PTV injectors in the solvent split mode described in this work consists of three steps: rapid injection of the sample, evaporation of the solvent, and splitless transfer of the analytes to the column. To prevent flooding of the liner the maximum sample volume has to be determined first. Then the splitless transfer step is optimized for small sample volumes. Finally, solvent elimination times and recoveries of analytes for large volume injections are determined.

\subsection{Maximum Sample Volume}

The maximum volume of liquid that can be injected at once into the cold PTV injector is determined by the volume of liquid that can be retained in the injector. This depends on the dimensions of the liner and the properties of the packing material. For a first estimation the maximum injection volume was determined visually. The liner was packed with glass wool and placed in the injector which was maintained at $30^{\circ} \mathrm{C}$. No column was installed and a helium split flow of $250 \mathrm{ml} / \mathrm{min}$ was applied. When injecting too large amounts of solvent, liquid was seen to occur at the bottom end of the injector. The maximum volumes so determined were later confirmed by analyzing increasing sample volumes and checking linearity of peak area plotted vs. injection volume. For hexane the maximum injection volumes were as follows: PTV-1 (length of glass wool plug $3 \mathrm{~cm}$ ), $20 \mu \mathrm{l}$ for the $1.2 \mathrm{~mm}$ i.d. liner packed with $4.5 \mathrm{mg}$ glass wool, $65 \mu \mathrm{l}$ for the $2.2 \mathrm{~mm}$ i.d. liner with $14.5 \mathrm{mg}$, and $165 \mu \mathrm{l}$ for the $3.4 \mathrm{~mm}$ i.d. liner with
$32.5 \mathrm{mg}$ glass wool. PTV-2 (length of glass wool plug $4 \mathrm{~cm}$ ), $150 \mu \mathrm{l}$ for the $2.3 \mathrm{~mm}$ i.d. liner packed with $34 \mathrm{mg}$ glass wool. PTV-3 (length of glass wool plug $5 \mathrm{~cm}$ ), $25 \mu$ for the $1.2 \mathrm{~mm}$ i.d. liner packed with $6 \mathrm{mg}$ glass wool. The values presented above should only be considered as a rough indication of the maximum sample volume. The liners could not be packed in a very reproducible way; for the larger i.d. liners deviations up to $25 \mu \mathrm{l}$ were found for the maximum injection volume after repacking with the same amount of glass wool.

A remark should be made here regarding the syringes. For the 100 and $250 \mu$ syringes used it was observed that liquid leaving the syringe needle was nebulized when the plunger was pressed down rapidly. This is probably beneficial because in this way there is no risk that a stream of liquid "pierces" directly through the glass wool packing and is then lost via the split exit at the bottom of the injector.

\subsection{PTV Splitless Injection}

In this work liners with varying internal diameters are studied for large volume sampling. As the liner i.d. also strongly affects the splitless transfer step, a brief discussion on some aspects important in splitless injection is appropriate here.

Injector overflow. In classical hot splitless injection injector overflow occurs when the volume of solvent vapor is too large to be accommodated in the liner [21]. This causes sample constituents to leave the injector via the septum purge or to penetrate into the carrier gas supply line. For this reason the injection volume in hot splitless injection is restricted to some $2 \mu \mathrm{l}$. In cold splitless injection the sample volume is restricted by the amount of liquid that can be retained in the liner. Here, injector overflow can occur if the solvent evaporates too fast. In contrast to hot splitless injection, overflow in cold splitless injection is generally less of a problem because the analytes are vaporized after the solvent, i.e. when the solvent vapor is escaping via the septum purge the analytes are still deposited on the glass wool. To confirm this, splitless injections of $5-30 \mu$ of alkane standards $\left(\mathrm{C}_{8}-\mathrm{C}_{20}\right)$ in five solvents were carried out using 2.3 or $3.4 \mathrm{~mm}$ i.d. liners and heating rates of $3-4 \%$. Quantitative recoveries of all $n$-alkanes were obtained indicating that vapor overflow is not a major source of concern here.

Sample transfer. For rapid and efficient transfer of the sample from the liner into the column dilution of sample vapors by diffusion in and mixing with the carrier gas should be kept to a minimum [22]. Minimum dilution is achieved by using narrow liners. This is visualized in Figure 1 where $2 \mu l$ of an alkane mixture in hexane were injected with the split valve closed during the entire run. Due to the higher carrier gas velocity in smaller i.d. liners the transfer of the compounds to the column is faster and occurs at lower temperatures (Figure 2). From this figure it can be seen that $75 \%$ of triacontane is transferred to the column at a temperature of $210^{\circ} \mathrm{C}$ for the $1.2 \mathrm{~mm}$ i.d. liner whereas $290{ }^{\circ} \mathrm{C}$ is required for the $3.4 \mathrm{~mm}$ i.d. liner. Besides the use of narrow liners the carrier gas velocity can also be increased by applying higher inlet pressures during splitless transfer. Here the use of a pressure programmable gas chromatograph is advantageous. A high inlet pressure for efficient transfer is applied during the splitless period, after which the inlet pressure is decreased to the optimum value for separation of the analytes. Rapid splitless 


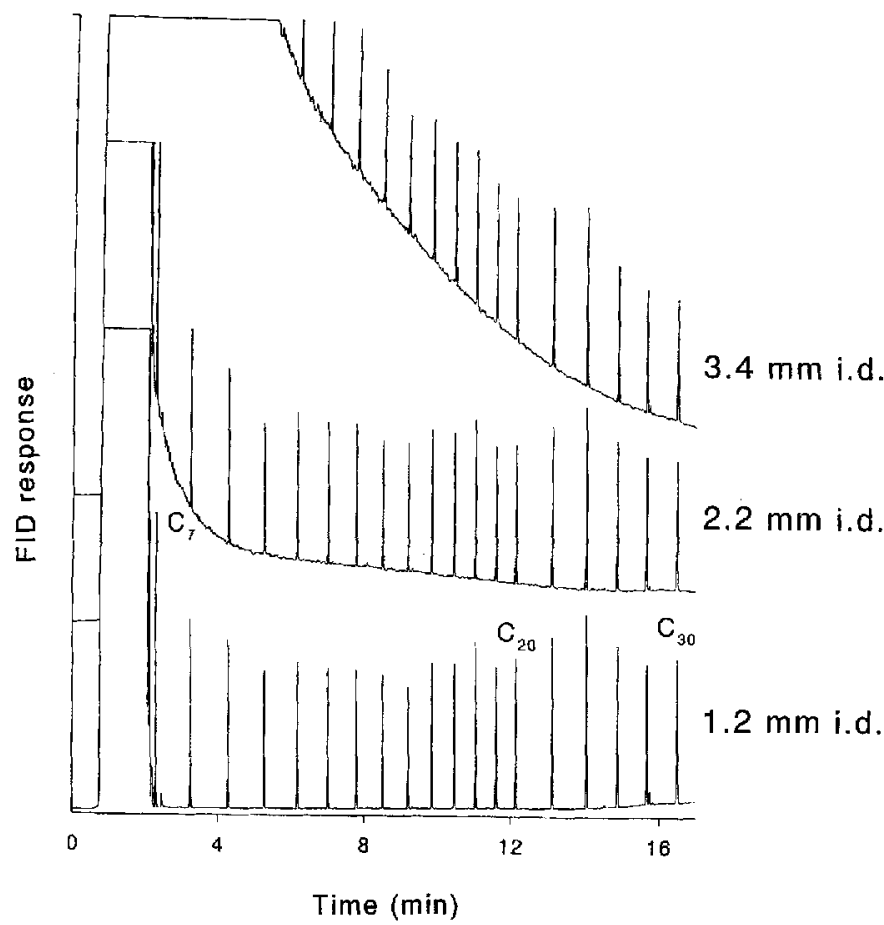

Figure 1. GC-FID chromatograms obtained after $2 \mu \mathrm{l}$ splitless injections of an $n$-alkane standard in hexane using three liners with varying internal diameters (PTV 1). The split valve was closed during the entire run. PTV: $30^{\circ} \mathrm{C} \rightarrow 8 \% \mathrm{~s}$ $\rightarrow 320^{\circ} \mathrm{C}$. GC: $40^{\circ} \mathrm{C}(1.5) 20^{\circ} / \min 320^{\circ} \mathrm{C}(1.5)$, inlet pressure $55 \mathrm{kPa}$.

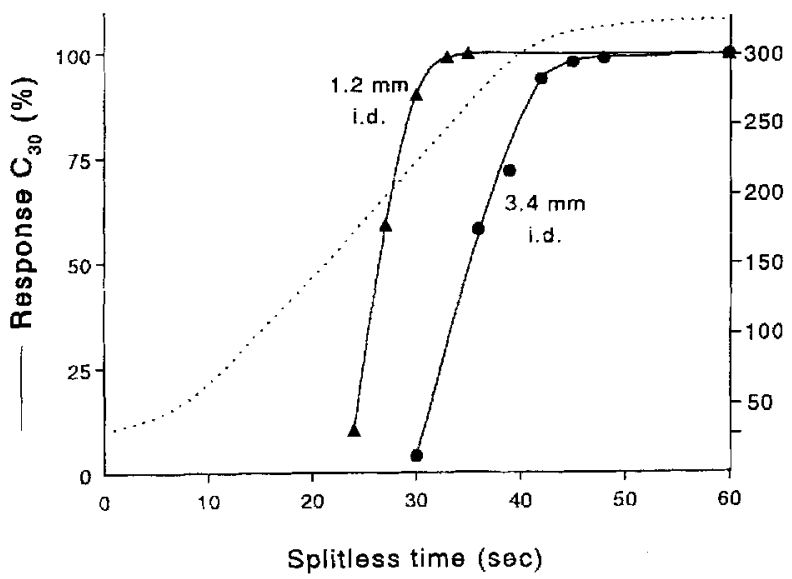

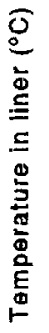

Figure 2. Effect of liner i.d. on transfer time and transfer temperature of $\mathrm{C}_{30}$ from the liner to the column. Conditions: see Figure 1. Dashed line: actual temperature inside the liner.

transfer can be important because of thermal degradation of sample components. Labile analytes can decompose in packed inserts. Often catalytic activity of the glass wool packing plays an important role in the degradation process $[6,18]$. To illustrate the effect of liner i.d. on degradation the response of silylated fatty acids obtained using cold splitless injection was compared with that observed in on-column injection. Degradation of trimethylsilyl esters is a very stringent test for hydrolytic activity which is mainly due to presence of silanol groups [23]. As is shown in Table 1, the least volatile silyl ester completely decomposed in all three liners. The recoveries of the other silyl esters improved as the liner i.d. decreased. This is due to the lower
Table 1. Recovery of silylated fatty acids ufter cold splitless injection in several glass wool packed liners.

\begin{tabular}{lllll}
\hline Liner internal diameter & \multicolumn{5}{c}{ Recovery (\%) $)^{\text {a) }}$} \\
& E10 & E14 & E18 & E22 \\
\hline $3.4 \mathrm{~mm}(34 \mathrm{mg}$ glass wol) & 70 & 29 & 0 & 0 \\
$2.2 \mathrm{~mm}(14 \mathrm{mg}$ glass wool) & 89 & 59 & 0 & 0 \\
$1.2 \mathrm{~mm}(7 \mathrm{mg}$ glass wool) & 95 & 89 & 26 & 0 \\
& \\
&
\end{tabular}

number of silanol groups and the shorter residence time in the smaller i.d. liner. Moreover, the esters leave narrow liners at a lower temperature.

Excessive solvent recondensation. With cold splitless injection it is in principle possible to introduce much larger volumes than with hot splitless injection. However, if the initial column temperature is below the pressure corrected solvent boiling point, excessive recondensation of solvent vapor in the column inlet may lead to peak distortion. Peak distortion could be observed for splitless injection of volumes larger than $4 \mu \mathrm{l}$ and was most pronounced for compounds of intermediate volatility (see Figure 3A). Part of these compounds enters the column together with the solvent. This part is spread by recondensed vapor and appears in the chromatogram as a broad shoulder eluting before the sharp peak. The sharp part of the peak originates from the solute fraction that entered the column after the solvent. In contrast, the more volatile $n$-alkanes enter the column together with the solvent, and sharp peaks appear in the chromatogram because the solute bands are reconcentrated by the solvent effect. High boiling compounds are not broadened because they leave the injector well after the solvent and do not enter the flooded column inlet.

Peak distortion due to excessive solvent recondensation can be prevented in several ways. The use of lower heating rates will improve peak shapes because a lower proportion of the (intermediate volatile) analytes will enter the column together with the solvent. An alternative is to vent the solvent via the column before heating the injector. With this approach we found that band broadening could be prevented for splitless injections up to $100 \mu \mathrm{l}$. Although quantitative recovery of all analytes was achieved (98-105\%, $\mathrm{C}_{8}-\mathrm{C}_{20}$ ), venting via the column was not very time efficient. Furthermore, compatibility with the detector may be a problem. Another way of preventing excessive solvent recondensation was to adjust the column temperature to a few degrees below the solvent boiling point as was also done by Grob [13]. In this case only a small volume of solvent recondenses, too little for flooding the column but still enough for reconcentrating volatile analytes by solvent trapping. The most convenient way to prevent excessive recondensation was the use of higher column flow rates as is illustrated in Figure 3B. Prior to splitless injection the inlet pressure was increased to $200 \mathrm{kPa}$, corresponding to a column flow of $c a 11 \mathrm{ml} / \mathrm{min}$, and after $1 \mathrm{~min}$ the pressure was decreased again to $50 \mathrm{kPa}$ for $\mathrm{GC}$ separation of the analytes. Sharp peaks are obtained because the high carrier gas flow during splitless transfer accelerates evaporation of the recondensed vapor in the column inlet which reduces the length of the flooded zone. Despite these promising results, for practical reasons constant inlet pressures were used in further experiments. 

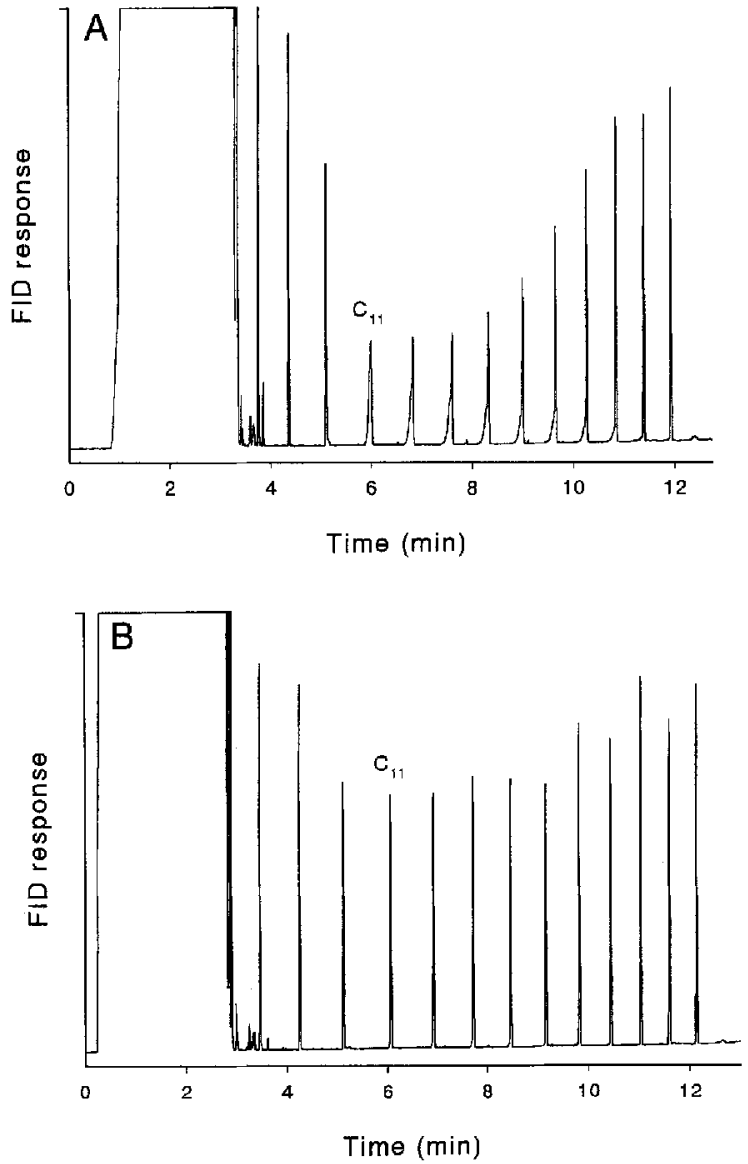

Figure 3. GC-FID chromatograms obtained after splitless injection of $15 \mu \mathrm{l}$ of an $n$-alkane standard $\left(\mathrm{C}_{8}-\mathrm{C}_{20}\right)$ in hexane. $\left.\mathrm{A}\right)$ inlet pressure constant at $50 \mathrm{kPa}$. B) elevated inlet pressure during splitless transfer: initial inlet pressure $200 \mathrm{kPa}$, after 1.0 min decreased to $50 \mathrm{kPa}$. PTV-1 with $3.4 \mathrm{~mm}$ i.d. liner: $50{ }^{\circ} \mathrm{C} \rightarrow 4 \% \mathrm{~s}$ $\rightarrow 300^{\circ} \mathrm{C}$, splitless time $1.0 \mathrm{~min}$. GC: $40^{\circ} \mathrm{C}$ (1) $20^{\circ} / \mathrm{min} 280^{\circ} \mathrm{C}$.

\subsection{Solvent Split Injection}

Cooling effects. The time needed for elimination of the solvent prior to splitless transfer of the analytes to the column is determined by the evaporation rate of the solvent. The evaporation rate of the injected liquid is proportional to the mole fraction $\left(x_{\mathrm{j}}\right)$ of solvent vapor in the purge gas and to the total gas flow leaving the injector. Assuming this gas is saturated with solvent vapor and the solvent vapor behaves as an ideal gas, the evaporation rate can be described by:

$F_{\mathrm{j}}=F_{\text {split }} \times x_{\mathrm{j}}=F_{\text {split }} \times \frac{P_{\mathrm{j}}}{P_{\text {in }}}$

where $F_{\mathrm{j}}$ is the evaporation rate in $\mathrm{mol} / \mathrm{min}, F_{\text {split }}$ the split flow in $\mathrm{mol} / \mathrm{min}, P_{\mathrm{j}}$ the vapor pressure of the solvent at the initial liner temperature and $P_{\text {in }}$ the inlet pressure. Unfortunately, this equation is not very useful to calculate the real solvent elimination rates because evaporation can cause considerable cooling of the liner. Cooling occurs because the heat capacity of the glass wool packed liner is low and heat transfer from the liner wall to the evaporation site is slow. The strongest cooling effect was measured just below ( $c 55 \mathrm{~mm}$ ) the tip of the syringe needle. When the solvent had been evaporated completely the temperature returned to the initial PTV temperature. Further down in the

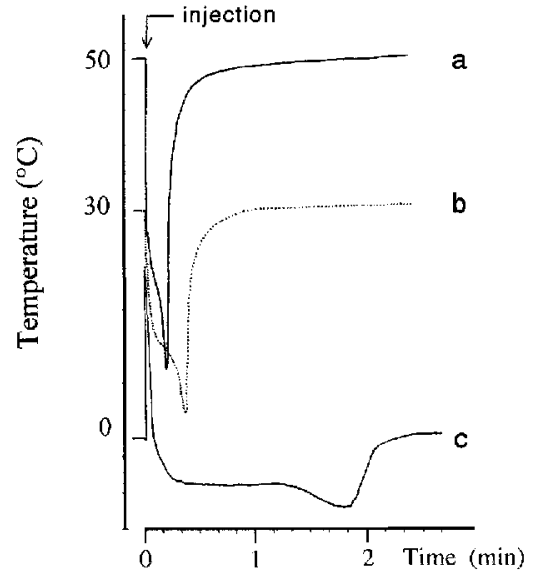

Figure 4. Temperature inside the liner after injection of $100 \mu$ of hexane at various initial PTV temperatures. PTV-1 with $3.4 \mathrm{~mm}$ i.d. liner. Helium split flow $250 \mathrm{ml} / \mathrm{min}$, ambient inlet pressure, initial temperatures: a) $50^{\circ} \mathrm{C}$, b) $30^{\circ} \mathrm{C}$ and c) $0{ }^{\circ} \mathrm{C}$.

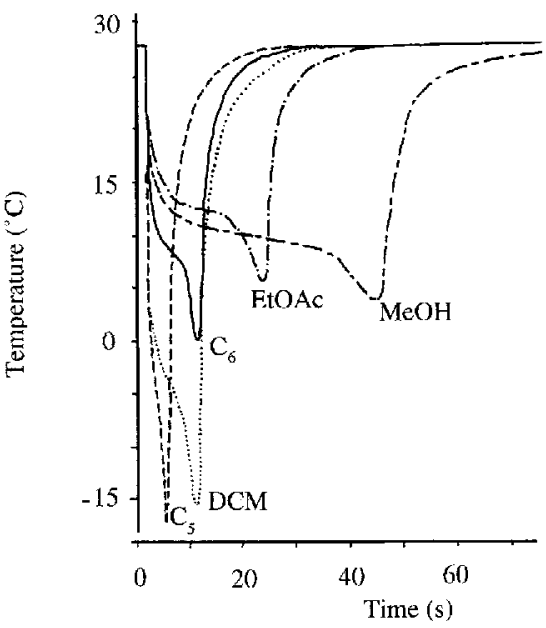

Figure 5. Temperature inside the liner after injection of $100 \mu 1$ of an organic solvent. $\mathrm{C}_{5}=$ pentane, $\mathrm{DCM}=$ dichloromethane, $\mathrm{C}_{6}=$ hexane, EtOAc $=$ ethyl acetate and $\mathrm{MeOH}=$ methanol. Initial PTV temperature: $30^{\circ} \mathrm{C}$; other conditions, see Figure 4.

packing the temperature decrease was less but it took more time to return to the initial value which indicates that vaporization takes place from the rear of the sample plug. By measuring the temperature in the liner with the thermocouple (positioned just below the syringe needle) the influence of several experimental parameters on the cooling effect could be studied. The degree of cooling depends on the evaporation rate which is strongly affected by the vapor pressure. This parameter in turn is determined by the PTV temperature and the solvent injected. Cooling effects at different initial PTV temperatures and for different solvents are shown in Figures 4 and 5. The temperature in the liner decreases until evaporation is so slow that cooling is compensated by heat transfer from the insert wall. The cooling effect is more pronounced at higher initial liner temperatures and for volatile solvents. In contrast to expectations, the decrease in temperature was found to show no correlation with values for the heat of evaporation [24] which are 53,104, 53, 79 and $208 \mathrm{cal} / \mathrm{ml}$, for pentane, dichloromethane, hexane, ethyl acetate and methanol, 
respectively. Due to cooling calculated evaporation rates and experimental values were found to differ up to a factor of three.

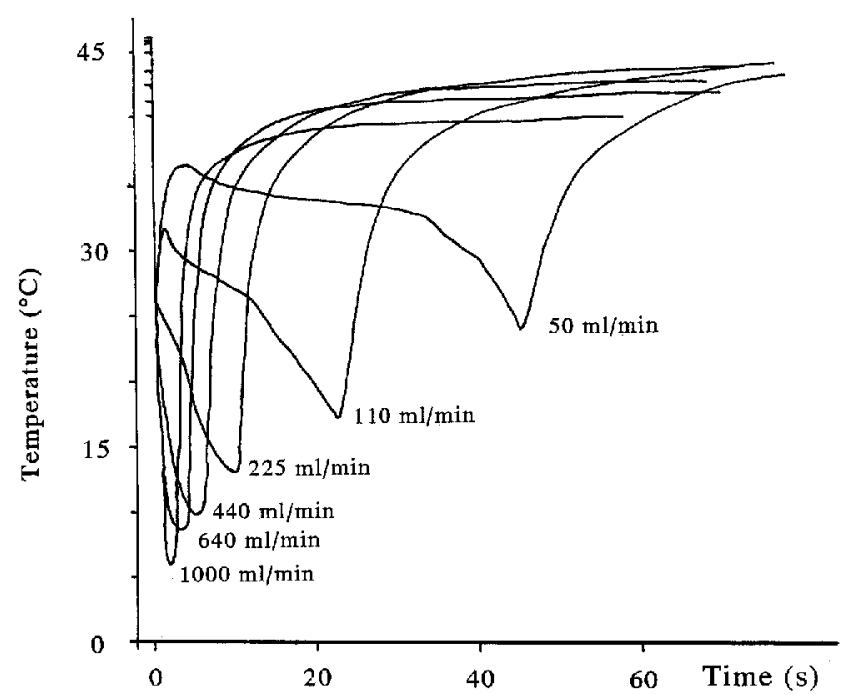

Figure 6. Temperature inside the liner after injection of $100 \mu \mathrm{l}$ of hexane at varying split flows. PTV-2 with $2.3 \mathrm{~mm}$ i.d. liner. Initial PTV temperature $50^{\circ} \mathrm{C}$, ambient inlet pressure.

The effect of the split flow on the cooling effect and on the evaporation time is shown in Figure 6. The higher the split flow the faster is the evaporation and the stronger is the cooling. For hexane at an initial injector temperature of $45^{\circ} \mathrm{C}$ the temperature drops 22 and $40{ }^{\circ} \mathrm{C}$ for split flows of 50 and $1000 \mathrm{ml} / \mathrm{min}$, respectively. For a more accurate determination of the effect of the split flow on the evaporation rate solvent elimination times for $100 \mu \mathrm{l}$ of hexane were determined by igniting the vapor leaving the split exit. When evaporation was complete the flame extinguished. The results are given in Table 2. The evaporation rate does not increase proportionally with the split flow due to a stronger cooling effect at higher split flow rates. The inlet pressure also affects the solvent elimination as illustrated in Table 3 .

Table 2. Effect of split flow on evaporation of $100 \mu 1$ of hexane ${ }^{\text {a) }}$.

\begin{tabular}{lll}
\hline $\begin{array}{l}\text { Split flow } \\
(\mathrm{ml} / \mathrm{min})\end{array}$ & $\begin{array}{l}\text { Evaporation } \\
\text { time (s) }\end{array}$ & $\begin{array}{l}\text { Evaporation } \\
\text { rate }(\mu \mathrm{l} / \mathrm{min})\end{array}$ \\
\hline 50 & 116 & 52 \\
100 & 60 & 100 \\
250 & 27 & 225 \\
400 & 18 & 336 \\
550 & 14 & 433 \\
\hline
\end{tabular}

${ }^{a}$ PTV-1 with $3.4 \mathrm{~mm}$ i.d. liner at $50^{\circ} \mathrm{C}$ and ambient inlet pressure.

Table 3. Effect of inlet pressure on evaporation of $100 \mu$ l of hexane ${ }^{\text {a) }}$.

\begin{tabular}{rll}
\hline $\begin{array}{l}P_{\text {in }} \\
(\mathrm{kPa})\end{array}$ & $\begin{array}{l}\text { Evaporation } \\
\text { time }(\mathrm{s})\end{array}$ & $\begin{array}{l}\text { Evaporation } \\
\text { rate }(\mu 1 / \mathrm{min})\end{array}$ \\
\hline 0 & 27 & 225 \\
50 & 34 & 176 \\
75 & 38 & 158 \\
100 & 49 & 134 \\
125 & 51 & 129 \\
150 & 55 & 109 \\
\hline
\end{tabular}

a) PTV-1 with $3.4 \mathrm{~mm}$ i.d. liner at $50^{\circ} \mathrm{C}$ and a split flow of $250 \mathrm{ml} / \mathrm{min}$.
At higher inlet pressures the mole fraction of solvent vapor in the gas leaving the injector is lower. As the split flow is constant (mass-flow controlled) this reduces the evaporation rate (equation 1). Again, the evaporation rate increases less than proportional with decreasing inlet pressures because faster evaporation is partially offset by lower values for $\mathrm{P}_{\mathrm{j}}$ due to stronger cooling.

Finally, the effect of the sample volume on solvent elimination was studied. For volumes of $25 \mu \mathrm{l}$ and larger the minimum temperature reached after injection is similar. As a consequence, for volumes exceeding $25 \mu$ the time needed for solvent elimination was found to be approximately proportional to the volume injected.

Recovery of $n$-alkanes from different solvents. In solvent split injection the analytes have to be retained in the liner while the solvent is vented via the split exit. When the liner is packed with glass wool the solutes are retained in the liner by two mechanisms: cold trapping and solvation. For intermediate and high boiling solutes, which can be quantitatively retained by cold trapping only, the procedure for large volume injections up to $150 \mu 1$ is very simple. Based on the results described so far a PTV injector equipped with a liner with an i.d. larger than $2.5 \mathrm{~mm}$ should be used applying a split flow preferably above 200 $\mathrm{ml} / \mathrm{min}$. The sample is injected rapidly in a cold injector with the split valve open. Splitless transfer is performed when the solvent has been vented completely. The moment of closing the split valve is not very critical provided it is not closed too early. Closing the split valve too late will hardly cause losses as the vapor pressure of the compounds is very low. For the determination of the vent time there are several possibilities. The easiest way is to ignite the vapor leaving the split exit. This works well for pentane, hexane (yellow flame) and ethyl acetate (weak blue flame), but not for dichloromethane and methanol. The method also fails when evaporation is very slow, i.e. at low initial PTV temperatures. A more sophisticated approach is to use a thermal conductivity detector as monitor [9], an approach which is applicable to all solvents. An alternative is to use the FID itself as monitor. In this case the column temperature is maintained above the pressure corrected boiling point of the solvent. Solvent entering the column during solvent splitting will reach the FID after the column dead time. When solvent evaporation is complete the FID signal returns to the baseline. The width of the solvent peak so obtained approximately equals the time needed for evaporation of the solvent. The procedure is demonstrated in Figure 7 which shows the injection of $100 \mu$ of an alkane standard in methanol. The first solvent peak in Figure 7 is in fact the monitor signal of the solvent elimination step; i.e. evaporation took approximately $1 \mathrm{~min}$. Next the analytes plus traces of residual methanol were splitlessly transferred to the column. Quantitative recovery was obtained for $\mathrm{C}_{17}$ and higher boiling $n$-alkanes (see Table IV below). From similar experiments carried out at lower PTV temperatures it was found that in order to retain $n$-alkanes in the liner by cold trapping only, the PTV temperature should be about $250^{\circ} \mathrm{C}$ below the boiling point of the solute. This means that at $50{ }^{\circ} \mathrm{C}$ quantitative recoveries are obtained from $\mathrm{C}_{17}$, at $30^{\circ} \mathrm{C}$ from $\mathrm{C}_{16}$ and at $0{ }^{\circ} \mathrm{C}$ from $\mathrm{C}_{14}$. It is evident that the use of lower initial temperatures makes solvent elimination more time consuming. 


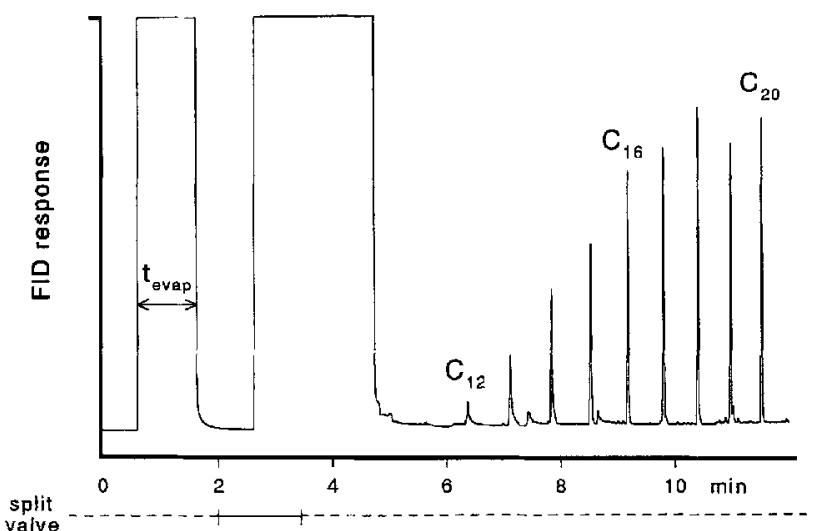

Figure 7. GC-FII) chromatogram obtained after a $100 \mu \mathrm{l}$ injection of an $n$-alkane standard $\left(\mathrm{C}_{8}-\mathrm{C}_{20}, 200 \mathrm{ppb}\right)$ in methanol. PTV-2 with $2.3 \mathrm{~mm}$ i.d. liner, initial temperature $50{ }^{\circ} \mathrm{C}$. Solvent split time: $2.0 \mathrm{~min}$, split flow $225 \mathrm{ml} / \mathrm{min}$. Splitless transfer: PTV $50^{\circ} \mathrm{C}$ ballistically to $300^{\circ} \mathrm{C}$, splitless time $1.5 \mathrm{~min}$. GC: $80^{\circ} \mathrm{C}$ (1) $20^{\circ} / \mathrm{min} 260^{\circ} \mathrm{C}$, inlet pressure $80 \mathrm{kPa}$. Split valve: dashed line $=$ open, solid line $=$ closed.

As an application the analysis of PCBs with GC-MS is shown in Figure 8. Obviously, detection limits at the ppt level are readily achievable in the SIM mode as indicated by the signal to noise ratio of the hexachlorobenzene and major PCB congener peaks.

For volatile analytes which can not be retained by cold trapping solely, solvation by the liquid in the liner can considerably improve recoveries. In this case the split valve should be closed slightly before the solvent has been completely eliminated because, with the last traces of solvent, the solvent trapping effect will disappear as well. Hence, the moment of closing the split valve is more critical. Closing the split valve too late will result in severe losses of volatiles while too early closure can lead to peak distortion due to excessive recondensation of solvent vapor in the column. The effect of the vent time on the recovery of volatile $n$-alkanes was studied by injecting $100 \mu \mathrm{l}$ of alkane standards in several solvents. Optimization of the solvent split time now starts with determining the time needed for complete

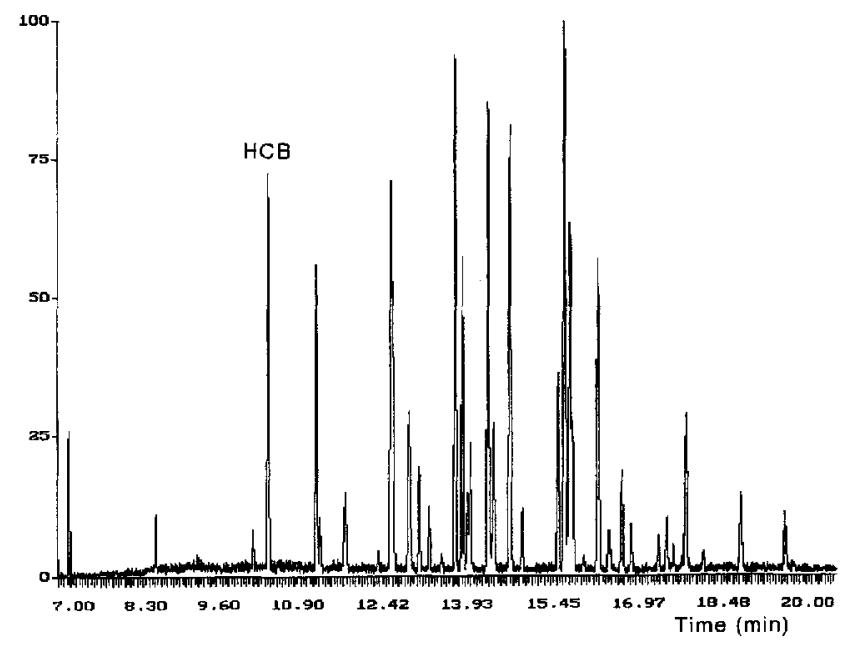

Figure 8. GC-MS (SIM mode) chromatogram obtained after a $100 \mu l$ injection of a hexane sample containing $20 \mathrm{ppb}$ Aroclor 1248 and $0.8 \mathrm{ppb}$ hexachlorobenzene (HCB). PTV-2 with $2.3 \mathrm{~mm}$ i.d. liner, initial temperature $50^{\circ} \mathrm{C}$. Solvent split time $30 \mathrm{~s}$, split flow $260 \mathrm{ml} / \mathrm{min}$. Splitless transfer: PTV $50{ }^{\circ} \mathrm{C} \rightarrow 3 \%$ $350^{\circ} \mathrm{C}$, splitless time $3.5 \mathrm{~min}$. GC: column: $25 \mathrm{~m} \times 0.25 \mathrm{~mm}$, i.d. $0.25 \mu \mathrm{m}$ CP-Sil-5, inlet pressure $135 \mathrm{kPa}, 50^{\circ} \mathrm{C} \mathrm{(2.5)} 30^{\circ} / \mathrm{min} 150^{\circ} \mathrm{C}(0) 5^{\circ} / \mathrm{min} 250^{\circ} \mathrm{C}$.

evaporation of the solvent as described above. Next the vent time is decreased in small steps. From these experiments it became clear that losses of volatiles mainly occur during elimination of the last $5-15 \mu 1$ of solvent. This is easily explained from Figures 4-6. With evaporation of the last portion of liquid both extra cold trapping due to the cooling effect and solvent trapping of the compounds in the liquid layer disappear rapidly. With optimal solvent trapping, i.e. using hexane as solvent for $n$-alkanes, it is possible to retain more than $95 \%$ of nonane after a $100 \mu$ injection in the solvent split mode (Table 4). A low initial temperature of $0{ }^{\circ} \mathrm{C}$ was applied here for efficient cold trapping. Besides, retention of the analytes in the hexane layer will be stronger at low temperatures. To accelerate evaporation venting was performed

Table 4. Recoveries of $n$-alkanes for $100 \mu$ injections using PTV injectors in the solvent split mode.

\begin{tabular}{|c|c|c|c|c|c|c|c|c|c|c|}
\hline \multirow{2}{*}{$\begin{array}{l}\text { Solvent } \\
\text { PTV No./liner i.d. (mm) }\end{array}$} & \multicolumn{4}{|c|}{ Hexane } & \multicolumn{2}{|c|}{$\mathrm{CH}_{2} \mathrm{Cl}_{2}$} & \multirow{2}{*}{$\begin{array}{l}\mathrm{C}_{5} \\
2 / 2.3\end{array}$} & \multicolumn{2}{|c|}{ Ethyl acetate } & \multirow{2}{*}{$\frac{\mathrm{MeOH}}{2 / 2.3}$} \\
\hline & $1 / 3.4$ & $1 / 3.4$ & $2 / 2.3$ & $3 / 1.2$ & $1 / 3.4$ & $2 / 2.3$ & & $1 / 3.4$ & $2 / 2.3$ & \\
\hline PTV initial temperature $\left({ }^{\circ} \mathrm{C}\right)$ & $0^{\mathrm{a})}$ & $0^{\mathrm{a})}$ & 50 & -30 & $0^{\mathrm{a})}$ & 30 & 0 & $0^{\mathrm{a})}$ & 50 & 50 \\
\hline Solvent split time (min) & 2.5 & 15 & 0.25 & b) & 1.75 & 0.5 & 0.1 & 4.0 & 0.5 & 2.0 \\
\hline $\mathrm{GC}$ initial temperature $\left({ }^{\circ} \mathrm{C}\right)$ & 40 & 40 & 40 & 40 & 40 & 30 & 30 & 40 & 95 & 80 \\
\hline Compound & \multicolumn{10}{|c|}{ Recovery $(\%)^{c)}$} \\
\hline Octane & 87 & 0 & 65 & 0 & 75 & 64 & 93 & 12 & d) & 0 \\
\hline Nonane & 97 & 7 & 74 & 11 & 82 & 76 & 91 & 53 & d) & 0 \\
\hline Decane & 94 & 24 & 80 & 15 & 91 & 91 & 87 & 78 & 68 & 0 \\
\hline Undecane & 98 & 47 & 83 & 25 & 93 & 90 & 90 & 87 & 81 & 0 \\
\hline Dodecane & 99 & 78 & 87 & 47 & 100 & 95 & 91 & 92 & 86 & 17 \\
\hline Tridecane & 99 & 94 & 89 & 76 & 103 & 99 & 93 & 95 & 91 & 40 \\
\hline Tetradecane & 103 & 101 & 92 & 93 & 105 & 101 & 97 & 100 & 95 & 66 \\
\hline Pentadecane & 101 & 100 & 92 & 98 & 102 & 102 & 98 & 100 & 95 & 80 \\
\hline Hexadecane & 101 & 99 & 97 & 97 & 100 & 100 & 98 & 102 & 97 & 86 \\
\hline Heptadecane & 102 & 101 & 101 & 97 & 100 & 102 & 100 & 105 & 99 & 97 \\
\hline Octadecane & 100 & 104 & 100 & 102 & 97 & 102 & 105 & 100 & 101 & 95 \\
\hline Nonadecane & 102 & 100 & 101 & 100 & 99 & 105 & 101 & 105 & 101 & 98 \\
\hline Eicosane & 103 & 96 & 100 & 101 & 100 & 100 & 102 & 105 & 100 & 95 \\
\hline
\end{tabular}

Split flow in all cases $250 \mathrm{ml} / \mathrm{min} .{ }^{\text {a) }}$ Inlet pressure during solvent elimination: ambient ${ }^{\text {b) }}$ Speed controlled injection as in ref. $6: 25 \mu / /$ min, after injection $45 \mathrm{~s}$ additıonal vent time. ${ }^{\text {c }}$ Recovery relative to $2 \mu$ l splitless injections. ${ }^{\text {d) }}$ Not separated from the solvent peak. 
at reduced (ambient) inlet pressure. The amount of hexane left in the liner when closing the split valve was estimated to be some $10 \mu \mathrm{l}$. At the PTV heating rate and the column flow applied splitless transfer of this volume did not lead to peak distortion due to excessive recondensation of solvent vapors in the column (Figure 9).

In Table 4 recoveries of $n$-alkane standards in five organic solvents are compared for $100 \mu \mathrm{l}$ injections under different conditions. A hexane injection at $0{ }^{\circ} \mathrm{C}$ was carried out with an excessively long vent time of $15 \mathrm{~min}$ to demonstrate that without solvation $n$-alkanes more volatile than $\mathrm{C}_{14}$ are partially lost. As

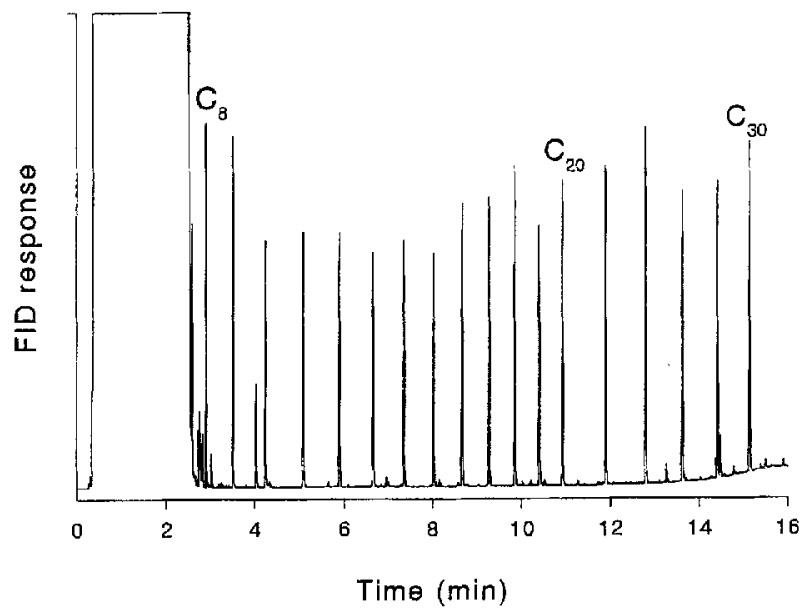

Figure 9. GC-FID chromatogram obtained after a $100 \mu 1$ injection of a $n$-alkane standard (C8-30, $200 \mathrm{ppb})$ in hexane. PTV-1 with $3.4 \mathrm{~mm}$ i.d. liner, initial temperature $0^{\circ} \mathrm{C}$. Solvent split time: $2.5 \mathrm{~min}$ at ambient pressure, split flow 250 $\mathrm{ml} / \mathrm{min}$. Splitless transfer: PTV $0{ }^{\circ} \mathrm{C} \rightarrow 4 \% \mathrm{~s} \rightarrow 325^{\circ} \mathrm{C}$, splitless time $1.5 \mathrm{~min}$. GC: $40^{\circ} \mathrm{C}$ (1) $20^{\circ} / \mathrm{min} 320^{\circ} \mathrm{C}$, inlet pressure $100 \mathrm{kPa}$.

shown above solvation in hexane greatly reduces losses of the volatile alkanes, even at higher initial PTV temperatures. For ethyl acetate and dichloromethane, which are less favorable solvents for $n$-alkanes, recoveries for the most volatile solutes are worse because solvent trapping is less efficient. For dichloromethane this is partially compensated by a stronger cooling effect and a shorter evaporation time.

As was stated above, when solvation is needed for retaining the analytes during solvent elimination, vent times are critical. However, even in this situation the repeatability was surprisingly good. Relative standard deviations (RSD) were $2-8 \%$ when recoveries were below $85 \%$ and better than $2 \%$ for higher recoveries. Only with methanol RSD values were slightly higher, $2-5 \%$. With correct venting times the injection volume, ranging from 25 to $150 \mu \mathrm{l}$, had no noticeable effect on the recovery. Besides, for $100 \mu$ injections no differences in recovery were found using either the $3.4 \mathrm{~mm}$ i.d. liner (PTV-1) or the $2.3 \mathrm{~mm}$ i.d. liner (PTV-2) under similar conditions.

\subsection{Comparison with Speed Controlled Sample Introduction}

For $100 \mu 1$ hexane samples the at-once injection was compared with speed controlled injection. In order to obtain good results for volatile analytes low initial PTV temperatures were used. At-once injection was performed as described above using the $3.4 \mathrm{~mm}$ i.d. liner at $0^{\circ} \mathrm{C}$. For speed controlled injection a liner with an internal diameter of $1.2 \mathrm{~mm}$ was used (PTV-3) at optimized conditions as described earlier [9], and a temperature of $-30{ }^{\circ} \mathrm{C}$ was used which allowed an introduction speed of $25 \mu \mathrm{l} / \mathrm{min}$. The recoveries are included in Table IV. For the speed controlled sample introduction it was expected that $n$-alkanes from $\mathrm{C}_{12}$ would be quantitatively retained by cold trapping because of the very low injector temperature. However, even for $\mathrm{C}_{13}$ a $25 \%$ loss was observed. On the other hand, when injecting a small volume of $5 \mu \mathrm{l}$ at once at $-30^{\circ} \mathrm{C}$, even after purging with a high helium flow for $15 \mathrm{~min}$ no losses were observed for $\mathrm{C}_{12}$. Adding pure hexane at a controlled speed after the $5 \mu \mathrm{l}$ injection again resulted in losses. These losses increased with the amount of hexane injected. Even the recovery of $\mathrm{C}_{14}$ was affected when more than $100 \mu \mathrm{l}$ of hexane were added. Consequently, the recovery of more volatile compounds is volume dependent [25] and a lower temperature will be generally needed for quantitative retention of the analytes in the liner during solvent elimination in speed controlled injection than with at-once injection. No explanation of these observations can as yet be forwarded.

Based on the results obtained in this work guidelines (Table 5) can be given for the selection of the PTV liner i.d. best suited for a given application. For thermolabile analytes narrow liners ( $\pm 1 \mathrm{~mm}$ i.d.) with small amounts of glass wool are best suited because the occurrence of degradation is kept to a minimum. The maximum volume that can be injected at-once in these liners is restricted to $c a 20 \mu \mathrm{l}$, for larger volumes speed controlled sample introduction has to be performed. For thermostable compounds the sample volume determines the choice of the liner i.d. and the introduction mode. For volumes up to $150 \mu \mathrm{l}$ the use of PTV injectors equipped with $\geq 2.5 \mathrm{~mm}$ i.d. liners allows at-once injection of the sample. As a consequence, no optimization of injection speed and no extra devices for sample introduction are required. In addition to this the application range is extended towards more volatile analytes. For sample volumes of over approximately $150 \mu \mathrm{l}$ the sample has to be introduced in a speed controlled manner. In this case there is no restriction with regard to the i.d. of the liner.

Table 5. Guidelines for the selection of liner i.d. and injection mode in large volume sample introduction using PTV injectors in the solvent split mode ${ }^{\mathrm{aj}}$.

\begin{tabular}{lllll}
\hline Analyte & Sample volume & Liner i.d. & Injection mode & Application range \\
\hline Thermolabile & $<20 \mu \mathrm{l}$ & $c a 1 \mathrm{~mm}$ & at-once & $\geq \mathrm{C}_{9}$ \\
Thermolabile & $>20 \mu \mathrm{l}$ & $c a 1 \mathrm{~mm}$ & speed controlled & $\geq \mathrm{C}_{14}$ \\
Thermostable & $<150 \mu \mathrm{l}$ & $c a 2.5-5 \mathrm{~mm}$ & at-once & $\geq \mathrm{C}_{9}$ \\
Thermostable & $>150 \mu \mathrm{l}$ & $c a 1-5 \mathrm{~mm}$ & speed controlled & $\geq \mathrm{C}_{14}$ \\
\hline
\end{tabular}

a) Liner packed with glass wool. 


\section{Conclusions}

Large volume sample introduction using PTV injectors in the solvent split mode is an attractive technique to improve analyte detectability in capillary GC. Two injection modes, i.e. at-once and speed controlled injection, can be applied depending on the sample volume, the volatility and also on the thermostability of the analytes. As regards the inner diameter of the liners, larger i.d. liners are advantageous because of their higher solvent capacity. Sample volumes up to $150 \mu 1$ can be injected rapidly preventing losses of volatiles down to nonane. On the other hand, smaller i.d. liners are more suited when analyzing thermolabile compounds. When the sample has to be introduced in a speed controlled way, i.e. for sample volumes exceeding some $150 \mu \mathrm{l}$ and also in coupled LC-GC systems, smaller i.d. liners are advantageous because of the efficiency of the splitless transfer of the analytes to the column.

\section{Acknowledgment}

The Foundation for Chemical Research in the Netherlands (SON) is gratefully acknowledged for their financial support (project No 700-344-009).

\section{References}

[1] K. Grob, "On-line coupled LC-GC", Huethig, Heidelberg, 1991.

[2] K. Grob, "On-column injection in capillary GC", Huethig, Heidelberg, 1987.

[3] H.-M. Müller and H.-J. Stan, J. High Res. Chromatogr. 13 (1990) 697-701.

[4] W. Vogt, K. Jacob, and H.W. Obwexer, J. Chromatogr. 174 (1979) 437-439

[5] W. Vogt, K. Jacob, A.-B. Ohnesorge, and H.W. Obwexer, J. Chromatogr. 186 (1979) 197-205.

[6] G. Schomburg in "Sample Introduction in Capillary Gas Chromatography", Vol. 1, P. Sandra (ed.), Huethig, Hcidelberg, 1985.
[7] F. Poy and L. Cobelli in "Sample Introduction in Capillary Gas Chromatography", Vol 1, P. Sandra (ed.). Huethig, Ileidelberg, 1985.

[8] J. Staniewski and J.A. Rijks, J. Chromatogr. 623 (1992) 105-113.

[9] J. Staniewski and J.A. Rijks, J. High Res. Chromatogr. 16 (1993) 182-187.

[10] F.J. Senorans, J. Tabera, J. Villen, M. Herraiz, and G. Reglero, J. Chromatogr. 648 (1993) 407-414.

[11] G. Schomburg, E. Bastian, H. Belau, H. Husman, F. Weeke, M. Oreans, and F. Muller, J. High Res. Chromatogr. 7 (1984) 4-12.

[12] J. Staniewski, H.-G. Janssen, and C.A. Cramers in "Proceedings of the 15th Int. Symp. on Capillary Chronatogr.", Riva del Garda, Italy, 1993, Huethig, Heidelberg, 808-813.

[13] K. Grob and Z. Li, J. High Res. Chromatogr. 11 (1988) 626-632.

[14] K. Grob, J. High Res. Chromatogr. 13 (1990) 540-546.

[15] K. Grob, S. Brem, and D. Fröhlich, J. High Res. Chromatogr. 15 (1992) 659-664.

[16] K. Grob and S. Brem, J. High Res. Chromatogr. 15 (1992) 715-722.

[17] K. Grob and D. Fröhlich, J. Jigh Res. Chromatogr. 16 (1993) 224-228.

[18] J.J. Vreuls, G.J. de Jong, R.T. Ghijsen, and U.A.Th. Brinkman, J. Microcol. Sep. 5 (1993) 317-324.

[19] H.G.J. Mol, H.-G.M. Janssen, C.A. Cramers, and U.A.Th. Brinkman, J. High Res, Chromatogr. 16 (1993) 459- 463.

[20] R. Kubinec, P. Kurán, I. Ostrovsky, and L. Soják, J. Chromatogr. 653 (1993) 363-368.

[21] K. Grob, Th. Läubli, and B. Brechbühler, J. High Res. Chromatogr. 11 (1988) 462-470.

[22] K. Grob, "Classical split and splitless injection in capillary GC", Huethig, lleidelberg, 1986.

[23] M. Donike, Chromatographia 6 (1973) 190-195.

[24] R.C. Reid, J.M. Prausnitz, and T.K. Sherwond, "The properties of gases and liquids", McGraw-Hill, New York, 1977

[25] H.G.J. Mol, J. Staniewski, H.-G. M Janssen, C.A. Cramers, R.T. Ghijsen, and U.A.Th. Brinkman, J. Chromatogr. 630 (1993) 201-212. 